\title{
A CRISE AMBIENTAL E O PAPEL DA EDUCAÇ̃̃O: UM ESTUDO FUNDADO NA ONTOLOGIA MARXIANA
}

\section{Susana Jimenez* Emanoela Terceiro**}

RESUMO: Este artigo está associado a uma pesquisa em andamento que examina, de forma mais ampla, os paradigmas e políticas educacionais emanados do Projeto de Educação para Todos, tendo como referência a perspectiva da ontologia marxiana. Sob esse prisma, intenta oferecer elementos críticos introdutórios quanto ao tratamento conferido de forma dominante à questão da crise ambiental e seus desdobramentos na educação para o desenvolvimento sustentável. Nesse sentido, apresenta, em linhas gerais, o que de mais recorrente encontra-se sobre a problemática ecológica, revisitando acontecimentos expressivos da agenda ambientalista e pontuando, nesse contexto, o papel atribuído à educação. Com base nas contribuições de estudiosos atentos às relações entre ecologia, educação e o complexo da reprodução social, aponta para a superação da ordem vigente como condição imperativa de resolutividade dos problemas atinentes à sobrevivência da espécie humana, assim como da emancipação plena da humanidade.

Palavras-chave: Ecologia; Educação Ambiental; Ontologia Marxiana.

\section{ENVIRONMENTAL CRISIS AND THE ROLE OF EDUCATION: A STUDY BASED UPON THE MARXIAN ONTOLOGY}

ABSTRACT: The paper relates to a research study currently in progress, which analyses, in a broader way, the educational paradigms connected to a Project entitled Education for All, from the Marxian ontology point of view. In this sense, it attempts to offer some introductory critical elements to the dominant approach applied to the issue of environmental crisis and its implications to the education for sustainable development. To accomplish this task, it portrays, in general lines, the most current discourses on ecology, going over some significant events that compose the environmental agenda, placing in this context, the role of education. Based upon the contributions of some authors who establish the necessary relationships between ecology, education, and the complexity of social reproduction, it points out the need to overcome the present social order, as an imperative condition for the solution of problems concerning human survival, as well as, that of full emancipation of mankind.

Keywords: Ecology; Environmental Education; Marxian Ontology.

* Pós-Doutora em Educação pela Universidade Estadual de Campinas (UNICAMP); Professora da Universidade Estadual do Ceará (UECE); Diretora do Instituto de Estudos e Pesquisas do Movimento Operário (IMO/UECE).E-mail: susana_jimenez@uol.com.br

* * Mestranda do Programa de Pós-Graduação em Educação Brasileira da Universidade Federal do Ceará (UFCE). Pesquisadora colaboradora do Instituto de Estudos e Pesquisas do Movimento Operário (IMO/UECE.). E-mail: manuterceiro@gmail.com 


\section{Introdução}

O presente artigo vincula-se a uma pesquisa em desenvolvimento $^{1}$ que objetiva analisar, sob o prisma da crítica marxista, os paradigmas educacionais vigentes, ensaiando, nesse contexto, de modo mais particular, uma primeira aproximação aos pressupostos da Educação Ambiental.

É oportuno esclarecer que, no âmbito da referida pesquisa, o marxismo é assumido em sua dimensão ontológica, a qual, rigorosamente resgatada por Gyorgy Lukács² ${ }^{2}$, permite-nos compreender a essência ontohistórica do homem, fundada no trabalho, pelo qual este transforma o meio natural, cria o novo e, ao mesmo tempo, se cria como ser radicalmente novo: o ser social. Por esse prisma, o trabalho opera, através da dialética articulação materialidade-consciência, objetividade-subjetividade, uma ruptura com a esfera meramente natural, inaugurando o mundo propriamente humano. Dito de outro modo, a partir do trabalho como complexo fundante, vem à luz uma nova qualidade de ser, capaz de ação consciente e livre, com todos os heterogêneos e contraditórios desdobramentos que vão instituindo a evolução histórica dos homens e, por dentro desta, a relação homem-natureza. Cabe frisar, ademais, que, num movimento complexamente mediado, a reprodução social assume formas e direcionamentos distintos, fundamentalmente em função das necessidades geradas no contexto das relações de produção da vida material, estabelecidas no curso da história. Porém, isso não supõe a ação desencarnada de qualquer força determinista capaz de sobrepujar-se ao homem como sujeito de seu devir, uma vez que os complexos de mediações são sempre sintetizadores das relações objetividadesubjetividade, não se esvanecendo, jamais por completo, as possibilidades de escolha entre alternativas, garantidas ao homem como ser social.

A ontologia marxiana revela, com efeito, a dupla dimensão do trabalho, negando, por um lado, que este se reduza irremediavelmente ao trabalho abstrato, sua atual forma histórica, assumida sob o capital; e apontando, por outro, as possibilidades e condições de superação da alienação no horizonte da emancipação plena dos homens.

Nesse sentido, uma investigação ancorada na ontologia marxiana requer que se apanhe o complexo de determinações que estariam na base do surgimento e da evolução do fenômeno estudado, articulando-o, por 
conseguinte, ao processo de reprodução social em sua totalidade, no limite, exigindo que se alcance o coração das relações capitalistas considerando, ainda, como será melhor apontado adiante, que tais relações apresentam-se hoje sob a particularidade de uma crise estrutural do próprio sistema do capital. Rejeita, por essa ótica, elementos da esfera do determinismo tecnológico como explicação das profundas transformações que vêm, certamente, se abatendo sobre o mundo, na contemporaneidade, com destaque para o risco de uma hecatombe ecológica que paira já sobre a vida no planeta. Ao contrário, situa a evolução científicotecnológica no âmbito da atividade social dos homens e, como tal, em interconexão com as necessidades impostas pelo processo de acumulação do lucro. Resguarda-se, nesse entrelaçamento, é importante observar, a relativa autonomia da ciência e da tecnologia, como dos diferentes complexos derivados do trabalho, frente à totalidade do capital, o que garante o movimento da história e a possibilidade de ruptura com os fins postos no presente.

Em se tratando do complexo educacional, a investigação, perspectivada na ontologia marxiana, contrapõe-se também ao caráter redentor oportunamente atribuído à educação, mistificando-a como fator primeiro da mudança e da resolução dos formidáveis problemas que vitimam a humanidade, sem a devida consideração pela dinâmica dos interesses e das relações de classes. Por conseguinte, a análise dos eventos educacionais contemporâneos, em qualquer das suas manifestações, como, por exemplo, o Projeto de Educação para Todos e o conjunto de reformas pedagógicas daí decorrentes, até a política e o pensamento instituído sobre a educação para a sustentabilidade, aqui enfocada, implica, analogamente, destrinchar-se, sobre o pano de fundo das relações entre o trabalho, a educação e o complexo da reprodução social, em que medida e através de que mediações tais paradigmas e políticas situar-se-iam na trilha das exigências colocadas pelo sistema diante da crise atual.

Com base nesse entendimento, uma investigação assentada no marxismo aponta, em última análise, para a superação do capital. Não pode supor o aperfeiçoamento ou a humanização do capitalismo, uma vez que as mazelas sociais - da desigualdade à pobreza e à degradação ambiental - não se constituiriam propriamente defeitos - reparáveis em definitivo pela boa vontade pedagogicamente cultivada no seio da sociedade civil ou pela ação de governos ou parlamentos porventura bem- 
intencionados - mas, pelo contrário, responderiam, predominantemente, a necessidades prementes do sistema vigente. Sem, de modo algum, desprezar a ação política voltada para a conquista de melhorias nos diversos âmbitos da sociabilidade imediata, pressupõe que a resolutividade plena dos problemas da vida humana, em suas mais profundas dimensões, situa-se radicalmente para além da lógica da mercadoria.

Nesse sentido, partimos do pressuposto de que as questões relacionadas à crise ecológica, em que se incluem os movimentos ambientalistas e a inserção da educação como estratagema na campanha verde, são, em última análise, subjacentes ao complexo social estruturado sob o capital.

Delineados sumariamente os elementos conceituais que orientam o tratamento onto-marxista quanto aos pressupostos do ambientalismo e da Educação Ambiental, no contexto dos paradigmas educacionais vigentes, passemos à nossa exposição propriamente dita. Traçaremos, nesse sentido, considerações preliminares relativas à questão da crise ambiental, acercando-nos de acontecimentos expressivos da agenda ambientalista; articulando à dinâmica de movimentos e debates mundiais a respeito da questão em foco a dimensão educacional; e, por fim, fornecendo, de modo mais sistemático, elementos introdutórios a uma crítica marxista sobre o tratamento vigente atribuído à sustentabilidade ambiental e seus desdobramentos na educação. Três autores situados, cada um a seu modo, no campo das relações entre marxismo e ecologia nos servirão, fundamentalmente, de base quanto a essa última empreitada, a saber: Bellamy Foster (2005), Guillermo Foladori (1997; 2002) e István Mészáros (1995; 2002). Nossas anotações críticas mais diretamente voltadas à Educação Ambiental se beneficiarão, por excelência, das indicações de Ivo Tonet (2007) que recuperam o devido nexo entre uma proposta de educação emancipadora e a superação do capital.

\section{Considerações sobre a crise ambiental}

Como ponto de partida, retomamos, de forma breve, a discussão sobre a ecologia, que, em alguma medida, desprendendo-se de sua gênese vinculada estritamente às ciências biológicas, trilha um caminho de independência em relação às suas raízes, adentrando pelo território de múltiplos complexos disciplinares e conformando-se como referência 
central para a reflexão sobre o futuro da humanidade, assumidamente comprometido pelos danos ambientais causados em anos de usos indevidos dos recursos naturais. Para melhor situar a questão, faz-se oportuno efetuarmos sucinta digressão acerca da construção histórica do conceito de ecologia.

Em 1866, o cientista alemão Ernest Haeckel inaugurou, na obra Morfologia Geral dos Organismos, o termo ecologia como proposta de uma nova disciplina científica cujo propósito seria estudar, no âmbito da biologia, as relações das espécies animais entre si e entre o ambiente orgânico e inorgânico. No entanto, o entendimento sobre esse termo não se deteve unicamente sobre a intenção do proposto por seu idealizador, tomando maiores proporções e espraiando-se para além do que foi a priori pretendido. A ecologia saiu, então, da esfera das atividades acadêmicas e alcançou os movimentos e discursos sociais em torno do mundo, alcançando, algumas vezes, intensa expressão política.

Tal transcurso, como se pode presumir, não aconteceu, ainda que advirtam sobre a rapidez de suas extensões, de forma simples. Pelo contrário, uma vez ultrapassando os contornos originais colocados por seu criador, o pensamento ecológico complexificou-se em significativos desdobramentos. No campo biológico, tem-se o incremento dos métodos e conceitos, enquanto no campo das ciências sociais, desenvolve-se, por exemplo, a chamada Ecologia Social, que se envereda "por um vasto enfoque multidisciplinar" (LAGO; PÁDUA, 2006, p. 9). Assim, conforme esclarecem os autores

Para entender o desenvolvimento do pensamento ecológico e a maneira como ele chegou ao seu atual nível de abrangência, é necessário partir da constatação de que o campo da Ecologia não é um bloco homogêneo e compacto de pensamento. Não é homogêneo porque nele vamos encontrar os mais variados pontos de vista e posições políticas e não é compacto porque em seu interior existem diferentes áreas de pensamento, dotadas de certa autonomia e voltadas para objetos e preocupações específicas. (LAGO; PÁDUA, 2006, p. 13)

\section{Não obstante, arrematam:}

É importante ter em mente, contudo, que essas diferentes áreas do pensamento ecológico não são compartimentos estanques, isolados entre si. No fundo, elas são diferentes facetas de uma mesma realidade e se 
complementam mutuamente (...) Para se ter uma visão completa e fecunda do campo da Ecologia, contudo, é importante ter uma perspectiva global, examinando-se as especificidades e a evolução de cada área em função da sua relação em conjunto. (LAGO; PÁDUA, 2006, p. 16-17)

Nesse sentido, é levada a crédito a ideia de que, a despeito das diferenças, o quadro do pensamento ecológico tem um ponto fundamental de convergência, qual seja, a preocupação quanto ao futuro histórico da humanidade. Ademais, há que se destacar, surgem ainda, de forma difusa, os movimentos ecológicos, que, do mesmo modo, envolvem vários matizes de concepções e intuitos ou, dito de outra forma, abrangem diversas correntes de pensamento, mas que, ao cabo, têm como preocupação primeira a conservação do meio ambiente e, em decorrência, o futuro da nossa espécie. Portanto, cabe notar que movimento ecológico, movimento verde, ambientalismo, etc. aparecem como afluentes de um amplo movimento social em que estão inseridas instituições, organizações não-governamentais, simpatizantes, ativistas e militantes políticos, cuja ação, apenas reiterando, orienta-se pela proteção do meio ambiente, neste contexto, causa considerada estreitamente ligada aos problemas sociais.

Diante da amplitude tomada pelo domínio da ecologia e das variedades de movimentos ecológicos, Lago e Pádua (2006) admitem que se avoluma o contingente de pessoas interessadas pela questão e, ao mesmo tempo, se fariam cada vez mais notáveis os debates políticos e as mudanças de comportamento dos mais diferentes grupos sociais frente ao problema, que envolveria, em última análise, a incerteza quanto ao futuro da humanidade, incerteza essa decorrente do esgotamento dos recursos naturais.

Com efeito, o pós-1945 inaugura, no quadro das prioridades mundiais, a preocupação com a questão da crise ambiental, marcando o início de uma fase de generosas discussões quanto ao modelo vigente de desenvolvimento e crescimento econômicos, acenando já, em alguma medida, para seus efeitos sobre o planeta. Essas discussões intensificamse em diferentes níveis e espaços decisórios a partir da década de 1960, quando os discursos volvem-se decisivamente para o binômio meio ambiente-desenvolvimento.

É, pois, a partir da constatação dos impactos ambientais negativos resultantes das ações do homem sobre a natureza, sobretudo com o advento do industrialismo e de suas contradições, que surge a 
Ecologia Social, conforme Lago e Pádua (2006). O pensamento ecológico deixa, então, a esfera estritamente natural e amplia seu foco para abranger também as interações entre homem-natureza ou sociedade e meioambiente.

A publicação de Silent Spring (Primavera Silenciosa), de Rachel Carson, em 1962, representou, sem dúvida, um marco ao denunciar os estragos causados pelo uso de agrotóxicos que diminuíam a qualidade de vida das populações. A obra tornou-se um clássico na história literária ambientalista. Daí então os debates foram travados tendo em vista o mundo material como base sem a qual todos os seres não poderiam existir e tampouco perpetuar a existência de suas respectivas espécies.

Outra marcante produção que aqui convém lembrar intitulou-se Os Limites do Crescimento, publicada em Roma, em 1968, cujo objetivo central era empreender uma análise a respeito do complexo de problemas que atinge as populações, tais como miséria, urbanização desenfreada, desemprego, instabilidade econômica; bem como um estudo sobre o consumo e as possibilidades, por parte do planeta, de suportar os desgastes daí decorrentes. O texto da obra circundava, portanto, as questões relativas à degradação do meio ambiente e os limites de desenvolvimento dos homens.

Nesse ínterim, a problemática da crise ambiental moveu não somente as averiguações teóricas, como já mencionado, mas os chamados movimentos ecológicos apareceram como fruto de uma série de ações sociais concretas.

Um fato digno de nota vinculou-se ao histórico protesto da tripulação do navio Phyllis Cormack, em 15 de setembro de 1971, contra os testes nucleares levados a efeito pelos Estados Unidos nas Ilhas Aleutas (Amchitka), no Pacífico Norte. Esse episódio, como é sabido, demarcou a fundação do Greenpeace, configurando, nesse sentido, um momento emblemático no trato da questão relativa à preservação do meio ambiente. Pela primeira vez na história recente da humanidade ocorria uma mobilização desse caráter. Era o princípio do que, adverte-nos Cascino (2000), mais recentemente, passou-se a denominar de consciência ou cidadania planetária.

$\mathrm{Na}$ evolução histórica da questão ambientalista, não podemos deixar de mencionar a criação do Programa das Nações Unidas para o Meio Ambiente (PNUMA), em 1972. No mesmo ano, promovida pela 
ONU, de 5 a 16 de junho, na Suécia, a Conferência de Estocolmo ou a Primeira Conferência Mundial sobre o Meio Ambiente reúne chefes de 113 Estados no debate sobre os vínculos existentes entre desenvolvimento e meio ambiente. Nesse momento, são travadas acaloradas discussões até o firmamento das bases de compreensão da questão em foco, a qual, ao fim e ao cabo, rejeitava tanto as abordagens malthusianas quanto as cornucopianas ${ }^{3}$ e optava por uma resolução equidistante entre ambas as posições, consignada no assim denominado ecodesenvolvimento.

A concepção de ecodesenvolvimento abranda, então, a polêmica gerada entre defensores do "crescimento zero" e defensores do "crescimento desenfreado", com a proposta de desenvolvimento ecologicamente direcionado e, portanto, prudente. O exame do problema saltaria, pois, da esfera quantitativa para a qualitativa.

O termo "ecodesenvolvimento" passou a ser, então, amplamente divulgado e adotado mundo afora, balizando os sucessivos debates a respeito da questão ambiental. Mais recentemente, passou-se a dividir o emprego do referido vocábulo com a expressão "desenvolvimento sustentável", que teria sido usada pioneiramente por Robert Allen, em 1980, no artigo "How to save the world", e consolidada na Segunda Conferência Mundial sobre o Meio Ambiente, a ECO-92 ou RIO-92, realizada no Brasil.

Vinte anos após a Primeira Conferência Mundial, a RIO-92 ocorre assim que findada a Guerra Fria, dando cabo da alarmada ameaça comunista. O interesse agora volta-se para a relação entre crescimento econômico e meio ambiente. No cenário de belezas naturais em que se encrava nossa Cidade de São Sebastião, tentou-se colocar em pauta um renovado projeto planetário, firmando bases indissolúveis para o relacionamento harmônico, em escala mundial, entre crescimento econômico e preservação do meio ambiente. Para tanto, foi elaborado um plano de ação - a Agenda 21 - que fixava direitos e deveres individuais e coletivos no horizonte do desenvolvimento sustentável.

Antes de prosseguir, convém determo-nos numa breve averiguação acerca da concepção de desenvolvimento sustentável a nós fornecida por Camargo (2003). Ora, desenvolvimento usualmente é utilizado como sinônimo de crescimento. Assim, por exemplo, a menção a um país desenvolvido costuma remeter de imediato à ideia de uma 
comunidade com altos índices de produtividade, rendimento, acumulação, inovações técnicas, etc. No entanto, ainda que se constitua condição imprescindível para o desenvolvimento, o crescimento não é suficiente, uma vez que se refere a desdobramentos quantitativos, ao passo que o desenvolvimento demandaria, a rigor, melhorias qualitativas.

Sustentar, por sua vez, denota conservar, apoiar, amparar, impedir a queda. $O$ adjetivo sustentável, no caso, conforme a mesma autora, diz daquilo que se pode sustentar. E ainda, no campo da ecologia, o termo sustentabilidade remeteria à capacidade de suporte, no que se refere à relação recursos-população.

Não deixa Camargo (2003) de admitir que, tendo em vista as decorrências sociais e ambientais do processo histórico de desenvolvimento humano desde a Revolução Industrial, a expressão desenvolvimento sustentável pode soar ambígua. No entanto, ainda que carente de um consenso em torno de seu significado preciso, assenta-se a dita expressão no cerne do discurso ecológico.

Assim sendo, não é de se admirar a dedicação de tantos teóricos à empreitada de destrinchar os elementos que circundam o entendimento do desenvolvimento sustentável, muito menos surpreende o crescimento da literatura sobre tal temática

Em suma, desenvolvimento sustentável traduziria o novo paradigma de orientação quanto ao relacionamento da sociedade e da economia com a natureza, no sentindo de atender às necessidades do presente, com incremento da qualidade de vida, do progresso econômico, da justiça social e da qualidade ambiental, sem, no entanto, comprometer as chances de plena sobrevivência das gerações futuras pela devastação do meio-ambiente.

Em agosto de 2002, denominada RIO+10, outra Conferência Mundial acontece, desta feita na África do Sul, com o objetivo de conferir o andamento dos acordos firmados na RIO-92. Os resultados obtidos nesses dez anos de assinatura dos acordos foram declaradamente desanimadores, deixando evidente que os interesses econômicos sobrepujam, a um só tempo, os direitos humanos e a preservação ambiental, também segundo Camargo (2003).

Como expressão por excelência quanto às tentativas de firmar acordos mundiais, em nome da propalada sustentabilidade, talvez se possa destacar o igualmente apregoado Protocolo de Kyoto. Tratado 
internacional com apelo a rígidos compromissos com vistas à redução das emissões de gases que provocam o efeito estufa dos países industrializados, o Protocolo foi debatido e negociado em Kyoto, no Japão, em 1997, aberto para as assinaturas dos diferentes países em 1998 e, por fim, ratificado em 1999.

O documento, vale lembrar, conforme exposição lacônica, porém proveitosa, do periódico Folha Online $e^{4}$ prevê, para o período entre 2008 e 2012, a redução da emissão de, no mínimo, 5,2\% de gases-estufa em relação aos níveis aferidos em 1990, estabelecendo, contudo, padrões de redução diferenciados para os 38 países considerados os principais emissores de dióxido de carbono, entre outros gases da mesma categoria.

Para os países da União Europeia, por exemplo, a redução estabelecida foi de 8\% em relação aos gases emitidos em 1990, enquanto que, para países como China, Brasil e Índia, não foram estabelecidas metas de diminuição.

Estima-se que até 2100 a temperatura global possa ser reduzida entre $1,4^{\circ} \mathrm{C}$ e $5,8^{\circ} \mathrm{C}$, isso dependendo dos resultados das negociações após o período entre 2008 e 2012, já que muitas autoridades científicas afirmam que a redução de 5\% em relação aos níveis de 1990 está longe de ser suficiente diante da ameaça do aquecimento global.

Cabe destacar que o país que, em maior escala, emite gases que desencadeiam o nefasto efeito estufa - os Estados Unidos - retirou-se do Acordo em março de 2001, alegando que o engajamento com aqueles compromissos repercutiria negativamente na economia ${ }^{5}$.

A educação não seria deixada à parte dos debates e movimentos internacionais a respeito da questão ambiental. Muito ao contrário, ao complexo educacional seria aferido lugar de destaque na verde cruzada salvacionista.

\section{A educação frente ao desafio da sustentabilidade}

Logo no ano de 1945, nos estertores da II Grande Guerra, portanto, a expressão environmental studies (estudos ambientais) penetra no vocabulário dos profissionais do ensino na Grã-Bretanha, conforme reporta Dias (2004). 
Vinte anos adiante, ou seja, em março de 1965, a expressão environmental education (educação ambiental) é inaugurada na Conferência em Educação da Universidade de Keele, na mesma Grã-Bretanha. Naquele momento, estabeleceu-se o consenso de que a educação ambiental tornar-se-ia fundamental na formação de todos os cidadãos.

Dois anos depois, a fundação da Society for Environmental Education - SEE (Sociedade para a Educação Ambiental) vem traduzir um encaminhamento proposto na Conferência sobre Educação realizada no College of Education, também na Grã-Bretanha. O ano de 1967 é marcado ainda pela formação do Clube de Roma, reunindo um grupo de especialistas, entre eles alguns pedagogos, para discussão acerca do futuro da humanidade frente à crise ambiental. No mesmo período, que tem sua culminância em 1968, convém lembrar, irrompem manifestações estudantis pelo mundo inteiro, em protesto contra as condições de vida de modo geral. É em meio a essa efervescência que se dá, nos Estados Unidos, o lançamento do Journal of Environmental Education (Jornal da Educação Ambiental).

A década seguinte é deveras expressiva no que toca à questão do ambiente em conjunto com a educação, exibindo uma sucessão de medidas, entre as quais, ainda com base nas informações prestadas por Dias (2004), pontuamos as que se seguem. Os Estados Unidos aprovam uma lei sobre Educação Ambiental; o prefixo "eco" é introduzido na língua inglesa, possibilitando a composição de novas palavras (por exemplo, o vocábulo ecohouse, que se poderia traduzir como casa ecologicamente correta...); na Grã-Bretanha, publica-se o primeiro exemplar do Bulletin of Environmental Education; em resposta à Conferência de Estocolmo, a Unesco promove, na Iugoslávia, um Encontro Internacional em Educação Ambiental; assiste-se ao lançamento do International Environmental Education Programme (IEEP); no Brasil, são criados os cursos de pós-graduação em ecologia em universidades do Rio Grande do Sul, Amazonas, Brasília, Campinas e São Carlos; e, por fim, a Secretaria Especial do Meio Ambiente (SEMA) inicia a elaboração de um documento sobre Educação Ambiental focado no contexto socioeconômico-educacional brasileiro.

Os anos de 1980 assistem, por sua vez, ao Seminário Internacional sobre o Caráter Interdisciplinar da Educação Ambiental no Ensino de $1^{\circ}$ e $2^{\circ}$ Graus, na Hungria, ao Seminário sobre a Energia e a 
Educação Ambiental na Europa, realizado em Mônaco, bem como ao Décimo Aniversário do Programa Internacional de Educação Ambiental da Unesco-Unep, que teve como resultado a introdução da Educação Ambiental nos planos, políticas e legislação educacionais de mais de 40 países. A quadra em foco enfrenta, ainda, o terrível acidente de Chernobyl (1986), o maior da história da energia nuclear. A década encerra-se, no Brasil, com a promulgação da Lei n. 7735, que, em 1989, cria o Ibama Instituto Brasileiro do Meio Ambiente e dos Recursos Renováveis.

Ainda, no caso do Brasil, mais dez anos são decorridos até o estabelecimento da Lei n. 9795 (de 27 de abril de 1999), que dispõe sobre a Educação Ambiental, institui a Política Nacional de Educação Ambiental e dá outras providências, passando a ser conhecida como Lei da Educação Ambiental.

O discurso em torno da Educação Ambiental parece surgir, pois, como resposta às preocupações da sociedade com o futuro, propondo-se atingir todos os cidadãos por intermédio de um processo pedagógico abrangente, a fim de superar a dicotomia entre natureza e humanidade. A educação ocupa aí então uma função central no que diz respeito à melhoria das relações entre o homem e o meio ambiente.

O campo ambiental abraça um renque de práticas pedagógicas, religiosas e culturais que, ao se organizarem, conseguem coadunar grupos variados de indivíduos e propagar conceitos sobre temas ambientais.

Ao tomar o campo ambiental como referência, pode-se compreender as motivações, os argumentos, os valores, ou seja, aquilo que constitui a crença específica que sustenta um campo. [Assim, entende-se a questão ambiental] (...) enquanto identidade distintiva de um grupo e de um espaço social (CARVALHO, 2005, p. 53).

Nesse sentido de formação de campos de relações sociais em torno da questão ambiental, é possível pensar a noção de sujeito ecológico, enquanto "tipo ideal capaz de encarar os dilemas societários, éticos e estéticos configurados pela crise societária em sua tradução contracultural; tributário de um projeto de sociedade socialmente emancipada e ambientalmente sustentável" (CARVALHO, 2005, p. 54).

Não obstante a anuência comum da centralidade da educação como potencialmente promotora da melhoria das nossas relações com o meio ambiente, Sauvé (2005, p. 17) indica que existem diferentes abor- 
dagens e práticas no campo da Educação Ambiental e como estratégia de "apreensão das diversas possibilidades teóricas e práticas" sugere a elaboração de "um mapa deste 'território' pedagógico".

Em que pese a heterogeneidade do vasto campo da Educação Ambiental, aqui também se encontra um ponto fundamental de convergência. Em entrevista concedida ao portal do Instituto Ecofuturo ${ }^{4}$, organização não-governamental qualificada como Organização de Sociedade Civil de Interesse Público (OSCIP), que tem como mantenedora a companhia Suzano Papel e Celulose, de acordo com a apresentação da página, o professor Dr. Luiz Percival Leme Britto, docente da Universidade de Sorocaba, afirma que as formas Educação Ambiental, Ecopedagogia e Educação Sustentável dizem respeito "a um tipo de educação em que se considere a vida como bem humano maior".

Nesse sentido, como ativo porta-vOz da chamada educação sustentável, Gadotti (2000) reconhece que "a Ecopedagogia não se opõe à Educação Ambiental. Ao contrário, para a Ecopedagogia a Educação Ambiental é um pressuposto. A Ecopedagogia incorpora-a e oferece estratégias, propostas e meios para a sua realização concreta" (GADOTTI, 2000, p. 96).

Adverte-nos o autor que, tendo em vista a exacerbação da potencialidade destrutiva do capitalismo, seguida em realizações concretas também pelo que se afeiçoou chamar de socialismo ${ }^{7}$, a humanidade, pela primeira vez, encontra-se diante da possibilidade real de destruição da vida no planeta - diante da era do extermínio. É preciso, pois, ecologizar a economia, a pedagogia, a educação, a cultura, a ciência, etc. Daí, então, principiar-se-ia um novo projeto ou um novo paradigma de sociedade!

Tal projeto ou novo paradigma de sociedade, ainda no dizer de Gadotti (2000), despontaria a partir da tomada de consciência ecológica, que daria o norte a ser seguido e guarnição suficiente para essa nova e ousada empreitada planetária em busca da construção de um mundo cheio de boniteza, mais justo e mais humano, adotando termos do legado freireano, reconhecidamente caro ao autor.

Tendo em vista que os nossos atuais problemas, entre os quais notadamente destacam-se os problemas ambientais, são decorrentes, advoga o autor, da nossa maneira de viver, e esta, por sua vez, é inculcada pela educação, em especial a educação escolar, faz-se mister dirigir a educação a partir do princípio de sustentabilidade, recuperando, nesse 
movimento, a noção de totalidade. A educação do futuro é, pois, sustentável, cujas categorias basilares advêm do paradigma da complexidade", o qual aponta para outra lógica, em "resposta aos paradigmas clássicos (positivismo e marxismo), unificadores e homogeneizadores" (GADOT'TI, 2000, p. 40-41).

O prestigiado porta-bandeira da Pedagogia da Terra admite que o sistema capitalista é enormemente inconciliável com a proposta de sustentabilidade ou, conforme suas palavras, "O sonho de um capitalismo ecológico é insustentável” (GADOTTI, 2000, p. 59). Portanto, o sucesso da investida ecológica não é garantido unicamente por ações de conscientização quanto à necessidade de, por exemplo, fazer reflorestamento, despoluir os rios, aplicar a coleta seletiva e reciclar o lixo. É necessário também dar solução aos problemas sociais, isto é, coadunar as questões ambientais às questões sociais. Nesse quadro, a noção de desenvolvimento sustentável tem, pois, um “(...) componente educativo formidável: a preservação do meio ambiente depende de uma consciência ecológica e a formação da consciência depende da educação" (GADOT'TI, 2000, p. 79).

Há que se sublinhar, com o mesmo autor, que os componentes mais determinantes da insustentabilidade, tais como a expansão mundial da indústria, formas de cultivo mais intensas e agressivas, o crescimento da população global e a violação de seus direitos são, com efeito, adversário mais combativo frente às possibilidades da educação. Contudo, sem a educação, e, cabe inteirar, a educação sustentável, não é concebível uma mudança real referente ao trato com a Terra, no sentido de não mais encará-la unicamente "como espaço de nosso sustento e de domínio técnico-tecnológico, objeto de nossas pesquisas, ensaios e, algumas vezes, de nossa contemplação" (GADOT'TI, 2000, p. 84).

No momento em que se menciona a educação sustentável, não se têm em vista somente os processos que se dão nas carteiras das escolas e das universidades. Está convencido o autor de que "Processos não formais, informais e formais já estão conscientizando muitas pessoas e intervindo positivamente, se não solucionando, despertando para o problema da degradação crescente do meio ambiente" (GADOTTI, 2000 , p. 87). Complementa sua convicção o fato de que a educação, cada vez mais, agregaria forças na peleja pela sustentabilidade econômica, política e social. Nessa direção, postula o autor: "A sensibilização e a 
formação ético-política de setores cada vez maiores da opinião pública são essenciais para deslanchar um processo mais sólido e criar as condições sociais mais propícias que possibilitem a sustentabilidade social e econômica" (GADOTTI, 2000, p. 87).

A ecopedagogia põe-se, então, nesse movimento, aspirando, além de gerar uma nova compreensão sobre a educação, desenvolver e impulsionar novos olhares e atitudes dos cidadãos frente ao mundo, novas formas de pensar e agir a partir do cotidiano. Nesse sentido, cada momento da vida condensaria uma oportunidade de olhar com novo olhar e de agir com nova prática.

Entretanto, ainda que, em vários momentos, reconheçam que o potencial destrutivo gerado pelo modo de produção e da acumulação capitalista é o responsável pela colocação do mundo numa posição extremamente arriscada em relação à natureza, as formulações dos teóricos socioambientais, de modo geral, e dos defensores da ecopedagogia, em particular, não prosseguem, via de regra, rumo à explicação orientada radicalmente para além do capital, o que põe em foco, necessariamente, a superação da propriedade privada.

À vista disso, acompanhemos, a seguir, a exposição de alguns elementos que entendemos subsidiar, ainda que introdutoriamente, o reconhecimento quanto ao profundo enraizamento da referida questão no próprio metabolismo do capital, mormente no contexto da crise estrutural com que se defronta contemporaneamente esse sistema.

\section{Elementos da crítica marxista à questão ambiental e à ecopedagogia}

Tornou-se lugar-comum a alegação de que tantas transformações no mundo do trabalho, ocorridas, com maior ênfase, desde meados dos anos setenta do século passado, puseram em xeque o pensamento marxista e suas enunciações a respeito da centralidade do trabalho assalariado e do lugar da luta de classes no entendimento da sociedade atual. Tais alegações são, ainda, via de regra, estendidas às ruínas do chamado socialismo real e, da mesma forma, à crise ambiental, tidas como decorrências elucidativas das falhas do materialismo histórico e da teoria da mais-valia. No contexto da problemática ambiental, não 
faltam críticas asseverando que Marx tinha o desenvolvimento das forças produtivas como positivo em si mesmo, numa perspectiva prometeica, entendendo a natureza como objeto a ser domado e, mais, ignorando o papel desta na teoria do valor-trabalho. Todavia, a crítica de Marx à acumulação do capital aproxima-se, com efeito, de uma concepção harmônica com a natureza e condena duramente o domínio unilateral sobre a natureza imposto pelo capitalismo.

Essa é a tese defendida por Foster (2005), um dos mais profícuos estudiosos das relações entre o marxismo e a questão ecológica.

É oportuno, assim, submetermos a uma breve resenha os elementos pontuados pelo autor, na linha argumentativa presente em sua obra A Ecologia de Marx. Nela, Foster (2005) inicia por recuperar o artigo "Debates sobre a Lei dos Roubos de Madeira", escrito em 1842, pelo então editor da Gazeta Renana, no qual Marx já sinaliza criticamente contra a propriedade privada como mediação central na relação homemnatureza. Acompanha, a seguir, o percurso de Marx, desde sua tese de doutorado, defendida em 1841, sob o título A Diferença entre a Filosofia da Natureza de Demócrito e a de Epicuro, passando pela Crítica da Filosofia do Direito de Hegel e A Questão Judaica, de 1843; e pela Contribuição para a Crítica da Filosofia do Direito em Hegel: Introdução, de 1844. Aportando nos Manuscritos Econômicos e Filosóficos, de 1845, enfatiza encontrar-se ali compreendido que a alienação incide não apenas no objeto de trabalho, no processo de trabalho, na atividade transformadora e criativa que define a espécie humana e nos trabalhadores em relação aos outros, mas também, e inseparavelmente, na relação dos homens com a natureza interna e externa.

Com efeito, como também assinala Lukács a partir dos Manuscritos Econômicos e Filosóficos, Marx sempre tratou a natureza como uma extensão do corpo humano - o corpo inorgânico da humanidade -, entendendo, nas palavras de Foster (2005, p. 107-108), que os homens "produzem a própria história com a natureza em grande parte produzindo os seus meios de subsistência. A natureza assim assume significado prático para a humanidade".

Avaliando os teóricos da população, Marx foi, outrossim, "um crítico obstinado da intromissão da teologia natural, da idéia da providência e da moralidade paroquial estreita na economia política, sobretudo aquela representada por Malthus" (FOSTER, 2005, p. 153). De 
tal modo que a crítica à compreensão malthusiana da relação populaçãoterra torna-se um dos temas principais da sua economia política. Com o aporte do autor, pode-se assinalar, portanto, como momentos definidores da concepção materialista da história e da natureza o apartamento em relação ao materialismo contemplativo de Feuerbach, a crítica a Proudhon no que se refere à indústria e a crítica a Malthus no que se diz respeito à terra.

Por essa mesma época, Engels escrevia $A$ Condição da Classe Trabalhadora na Inglaterra. Compartilhando agudamente do interesse pela situação dos trabalhadores, Marx, ao lado de Engels, tece ácidas críticas às condições insalubres nas quais esses trabalhadores foram atirados nos porões da revolução industrial, sem sequer poder saciar as necessidades mais imediatas, aquelas mais próprias da espécie, de ordem fisiológica, como beber, comer e dormir. Assim, sua atenção volta-se crescentemente para a análise da luta de classes e da economia política, o que, por sua vez, sinalizou a necessidade de transcender o naturalismo feuerbachiano.

O rompimento com o materialismo feuerbachiano era necessário e ocorreu em 1845, com as Teses sobre Feuerbach. Nesse contexto, é inaugurada a articulação entre o materialismo mais prático e a concepção materialista de história. Para adiante, uma implicação do novo materialismo de Marx teria sido a passagem de foco da natureza para a história, sem, no entanto, negar a prioridade ontológica daquela, fator igualmente admitido por Lukács, em seus próprios termos?.

Em suma, de acordo com o que explica Foster (2005):

Não houve nenhum lugar na análise de Marx em que o domínio da natureza exterior tenha sido simplesmente ignorado. Porém, ao desenvolver o materialismo histórico, ele tendeu a mencionar a natureza apenas no limite em que ela era incorporada à história humana, pois era cada vez mais difícil encontrar uma natureza intocada pela história humana. Nesse particular, a força da análise de Marx residia na sua ênfase na qualidade da interação entre a humanidade com a natureza ou no que ele acabaria por chamar 'metabolismo' da humanidade com a natureza: através da produção. (FOSTER, 2005, p. 164)

Em suma, Marx e Engels teriam compreendido perfeitamente que o mundo material - a natureza - é condição sem a qual não há existência humana e que a natureza tampouco pode ser reduzida à história humana. Conscientes disso, prosseguem suas análises, partindo da 
produção dos meios de subsistência ao longo da história humana, produção essa que, é importante reiterar, relaciona estreitamente o mundo natural e o mundo social, remetendo-nos à categoria trabalho.

Prossigamos, então, com o aporte oferecido por Foladori (1997) sobre a questão ambiental. O referido autor reforça o estudo aqui empreendido, na medida em que considera a crítica de Marx à acumulação do capital como reivindicatória da sintonia com a natureza e, portanto, refutando qualquer acepção prometeica produtivista.

Na contramão das acusações correntes, assevera Foladori (1997), Marx e Engels censuraram o domínio unilateral sobre a natureza, de maneira especial aquele com o qual o capital bem se servia.

Conforme a prudente advertência do autor: "A magnitude da crise ambiental atual não pôde ser prevista por Marx, e não o foi. Mas tampouco pode-se atribuir-lhe um desinteresse pelo futuro do mundo natural" (FOLADORI, 1997, p. 145). Nesse sentido, ressalta o autor, Marx teria procurado entender o porquê da ruptura entre homem e natureza, reclamando a reconciliação desse laço no horizonte de uma terra sem proprietários $^{10}$.

Em anuência com a crítica marxista, discute o mesmo autor acerca dos "Avanços e limites da sustentabilidade social" (2002). Analisando o percurso da noção de desenvolvimento sustentável, assinala a consolidação, no cenário ambientalista, de uma visão fundamentalmente tridimensional, a partir da qual se incorporariam à ideia da sustentabilidade propriamente ecológica ou ambiental os aspectos sociais e econômicos.

Não obstante compreensiva abrangência de tal enfoque, para o autor "trata-se de uma visão tecnicista e, portanto, ideologicamente comprometida com o próprio capitalismo causador da degradação" (FOLADORI, 2002, p. 105), por conseguinte, conforme avalia, a preocupação com a sustentabilidade social, inserindo-se nesse espectro o problema da pobreza, está subsumida à preocupação com a insustentabilidade ecológica, a qual poderá comprometer "as possibilidades de o capitalismo continuar seu crescimento ilimitado" (FOLADORI, 2002, p. 104). Ademais, numa perversa equação calculada por organismos internacionais como a ONU e o Banco Mundial, o fato de que o aumento populacional faz-se mais intensivamente palpável por obra dos pobres, a pobreza acabaria por pressionar desmedidamente por 
recursos, além de incrementar os resíduos! $\mathrm{Na}$ mesma linha de análise, atesta ainda o autor: "Muitas vezes, as capacidades humanas e as relações sociais que dizem respeito à forma como se gera a pobreza e o desemprego não estão em discussão, senão suas conseqüências técnicas enquanto poluição e degradação do meio ambiente" (FOLADORI, 2002, p. 107).

O caráter tecnicista inferido ao tratamento do problema da sustentabilidade traria ainda à tona outros elementos correlatos, o que vale aqui destacar. Assim, conforme argumenta o autor, se, por um lado, as relações estabelecidas entre os homens e a natureza externa, de manipulação e transformação exibem caráter necessariamente técnico, por outro, tal processo encontra-se implicado em determinado contexto de relações sociais, mais precisamente relações sociais de produção. Isso ocorre "pelo simples fato de que os meios com os quais trabalham, sejam esses instrumentos, maquinaria, insumos ou os próprios espaços físicos nos quais se realizam as atividades, estão distribuídos segundo regras de propriedade e/ou apropriação" (FOLADORI, 2002, p. 107).

Como se tudo isso não bastasse, o autor vai mais longe em suas elucidações para apontar o desconcertante descompasso entre a proposta de políticas públicas participativas com vistas à redução da pobreza e à elevação da qualidade de vida, por um lado, e as políticas macroeconômicas determinadas pelas instituições internacionais, por outro, maiormente preocupadas em aprofundar as privatizações, reduzindo o gasto genuinamente público. Ironicamente, ainda que presumivelmente por oportuno e/ou mistificador, emana desses próprios organismos de proteção ao capital o discurso da democracia participativa como instrumento de alcance daqueles nobres propósitos.

Não seríamos justos com o autor se omitíssemos seu reconhecimento de que esses mecanismos e suas agências promotoras podem vir a solucionar importantes problemas localizados, por exemplo, "de fome ou doenças específicas", atuando, pois, "sobre as conseqüências de um processo de diferenciação e injustiça social” (FOLADORI, 2002, p 112). Há que se ter claro, porém, que esses processos de desenvolvimento sustentável não afetam as relações de produção, que geram, por sua vez, condições de insustentabilidade.

Encerramos nossa revisita ao autor em tela registrando um ponto por este levantado, o qual toca diretamente a questão educacional. 
Recupera Foladori (2002), nesse sentido, a significativa mudança de paradigma consumada nos finas do século passado, no seio da comunidade internacional, que desloca a ideia de melhoria do meio ambiente per se para o pólo do desenvolvimento do próprio homem, com vistas a torná-lo, assim, consciente e capaz de uma ação ecológica adequada.

De qualquer forma, sob a inspiração de Middleton e O’Keefe, por ele citados, o autor postula de forma conclusiva:

Enquanto os problemas da pobreza, justiça social e sustentabilidade social em termos gerais são resultados de uma forma de distribuição e propriedade dos recursos e dos meios de produção, os discursos mais avançados do desenvolvimento sustentável (...) continuam a trabalhar com a ótica do indivíduo. (...) $\mathrm{O}$ peso das relações sociais de produção capitalistas restringe as possibilidades de mudanças nas relações técnicas atingirem a esperada sustentabilidade social”. (FOLADORI, 2002, p. 112)

Decerto, e Marx obviamente disso estava ciente, a forma como as sociedades pré-capitalistas relacionavam-se com a natureza distingue-se imensamente da forma como o fazem as sociedades sob o jugo do capital. Para estas, a natureza figura como um bem material devidamente discriminado nas escrituras, a ser apropriado por membros selecionados da sociedade, conferindo aos compradores o status de cidadãos. Portanto, nessa forma de sociabilidade, a relação homem-natureza, como acertadamente apontam os autores revisitados, encontra-se constantemente mediada pelo capital.

Nesse cenário, contudo, um agravante de monta é acrescentado pelo terceiro autor, com quem pretendemos dialogar no escopo da crítica marxista. Este diz respeito às peculiaridades do capitalismo contemporâneo atreladas ao caráter estrutural da crise hodierna.

É necessário e urgente compreender o emaranhado de contradições fundado no antagonismo jamais conciliável entre capital e trabalho, em que se articulam, entre tantas, a contradição entre o desmedido crescimento da produção e a consequente destruição ambiental, nefastamente aguçada pelo processo globalizante do capital.

Como bem sabemos, por princípio, o ritmo de produção capitalista é tão intenso e incessante que, cada vez mais, o esgotamento dos recursos naturais torna-se iminente. 
Em linhas gerais, apesar de elementos-chaves do sistema do capital estarem presentes em formas de sociabilidade que antecederam a capitalista, foi nesta que o capital encontrou condição favorável para exercer seu domínio global como sistema social. Ora, nas formas de sociabilidade anteriores, a produção dirigia-se para o uso, enquanto no sistema capitalista, cuja base está fixada no capital, a produção sobrepõe aos valores de uso a necessidade imperiosa do valor de troca, ininterruptamente expansível. No entanto, essa insaciável e indiscriminada necessidade expansiva trouxe, atrelados, limites históricos insuperáveis.

Caímos aqui, de cheio, nas explicitações de Mészáros (1995; 2003) sobre a crise estrutural do capital.

Colocando de modo muito sumário a referida tese, de acordo com o discípulo de Lukács, o capital vem atravessando, nas últimas três décadas aproximadamente, uma crise significativamente mais complexa e severa do que as crises cíclicas que marcaram, até o passado recente, a vigência desse modo de produção, das quais o sistema conseguia, de um modo ou de outro, emergir para um novo, ainda que efêmero, período reprodutivo. A presente crise se teria alojado na própria estrutura do sistema de acumulação, arrastando-se em proporções globais e níveis de intensidade inédita. No esforço de reproduzir-se no quadro de uma crise que insiste em não querer dar tréguas, o sistema lança mão de mecanismos que, entre outras tragédias, como o desemprego, a degradação acentuada do trabalho e a mercantilização crescente da atividade social, aplica, de forma absolutamente desmesurada, o princípio da produção destrutiva (traduzido, em larga medida, na produção do descartável). Por tudo isso, o meio ambiente acaba pagando um ônus que beira o insuportável, colocando ao alcance da vista o próprio espectro da destruição global.

Diante desse cenário, não poderia ser mais dura a advertência de Mészáros (2003):

Não existem rotas conciliatórias de fuga. (...) Muitos dos problemas que teremos de enfrentar - desde o desemprego estrutural crônico aos graves conflitos econômicos, políticos e militares internacionais (...) e até a destruição ecológica generalizada, observada por toda parte - exigem ação combinada em futuro muito próximo. A escala temporal dessa ação talvez possa ser medida em algumas décadas, mas, certamente, não em séculos. (MÉSZÁROS, 2003, p. 108) 
Posicionando-se, a um só tempo, contra a aceitação submissa da ordem vigente e a propalada decrepitude do movimento revolucionário, conclui adiante o autor: "O tempo está se esgotando. Assim, somente uma alternativa radical ao modo estabelecido de controle da reprodução do metabolismo social pode oferecer uma saída da crise estrutural do capital” (MÉSZÁROS, 2003, p. 108).

Em concordância com Mészáros, para Tonet (2007, p. 28), é nesse quadro de crise que a educação deve ser pensada, conquanto "na medida em que a matriz do mundo, que é o trabalho, está em crise, a educação não poderia deixar de participar desta mesma crise."

Examinado o conjunto diversificado de respostas que vêm sendo oferecidas pelos teóricos da educação à presente situação, o autor identifica, fundamentalmente, duas perspectivas de análise. A primeira, tipicamente conservadora, ausenta-se de qualquer esboçamento crítico, indicando, basicamente, novos receituários que permitiriam formar novos sujeitos, ajustados às novas situações trazidas pelos ventos da mudança.

Consideremos com mais vagar a segunda classe de respostas, aquela caracterizada pelo autor como progressista, em cujo regaço cremos deitar-se com maior comodidade o paradigma da ecopedagogia.

Essa classe progressista de respostas descarrega, com efeito, pesada crítica sobre o neoliberalismo e a globalização. Nesse sentido, põe na conta desses dois fenômenos conjugados o agravamento de toda a gama de problemas sociais - e ecológicos, por certo - com que hoje nos defrontamos, deixando incólumes as determinações do próprio capital para cuja reprodução fez-se necessário, um dia, o modelo neoliberal. Como bem lembra o autor, aqui se situam aqueles educadores que apostam na possibilidade quanto ao advento de um novo mundo, mais justo e igualitário, para além do neoliberalismo, porém sem os incômodos da revolução, diga-se de passagem. A bem da verdade, poderíamos acrescentar, desconsideram estes que o próprio capital poderá amanhã, quem sabe, jogar às traças o modelo neoliberal - como, no passado, abandonou as prerrogativas do Estado de Bem-Estar Social, por exemplo - em nome de uma alternativa mais funcional a suas necessidades, sem fazer retroceder um milímetro que seja sua lógica reprodutivista. De todo modo, tratar-se-ia aqui, em suma, de, pelo poder da educação, controlar o capital, aperfeiçoálo, humanizá-lo, trazê-lo, enfim, ao bom senso, dobrando-o, contra suas próprias premissas, aos princípios da ética e da cidadania planetária. 


\section{Nota conclusiva}

Dois autores largamente citados ao longo do presente texto, Lago e Pádua (2006), não poderiam atestar com maior explicitude a inserção do tratamento dominante acerca da questão ambiental, como de resto, do paradigma da ecopedagogia, no movimento mais amplo de ofensiva ideológica que vem se abatendo contra o marxismo, que traz em seu bojo o abandono de suas categorias fundamentais - da centralidade do trabalho e da particularidade classista às condições - revolucionárias - de construção de uma sociedade sustentável e livre11.

Com todas as letras, esses autores reafirmam o revisionismo embutido nesse conjunto de proposituras, assinalando que ainda que não pretendam ter em mãos um projeto com respostas prontas os ecologistas sustentam, de modo geral, que não há de se encontrar solução para os atuais problemas afetos à degradação do meio ambiente em investidas antigas, sequer remotamente articuladas ao complexo da luta de classes, ou apelando à superação do sistema da mercadoria e da propriedade privada. Ao contrário, a solução emergiria de baixo para cima, do engajamento e das iniciativas de homens e mulheres comuns, que almejam a possibilidade da construção de um mundo melhor, para tanto se dispondo a arguir seus modos de vida, de trabalho, de consumo e, ainda, suas formas de relacionamento, seus entretenimentos, suas percepções e posicionamentos face ao mundo.

Sem dúvidas, a alternativa de mudança nas relações sociais de produção é tipicamente deixada de lado nas elaborações relativas ao pensamento e às políticas vigentes em torno da sustentabilidade, aí incluída a educação sustentável ou ecopedagogia. Desse modo, o apelo a um novo paradigma de sociedade e de educação estende um manto de silêncio sobre a necessidade de superação da propriedade privada que, não haveria como negarmos, avança com crescente avidez sobre os recursos do planeta. Assim, tais projetos de mudança giram nos contornos da ciranda das próprias relações capitalistas, sem levar em conta que estas colocam limites estruturais insuperáveis à efetivação do ecodesenvol-vimento - e, por derivação, da ecopedagogia.

Em suma, as vozes críticas que se levantam em favor da salvação do planeta, conquanto legítimas, não transcendem, via de regra, o nível das manifestações fenomênicas, desocupando-se do exercício de arrancar pela raiz os determinantes do real. 


\section{Referências}

BBC BRASIL. Entenda os principais pontos do Protocolo de Kyoto. Folha Online. 16 fev. 2005. Disponível em:

<http://www1.folha.uol.com.br/folha/bbc/ult272u39714.shtml> Acesso em agosto de 2009.

CAMARGO, Ana Luiza de Brasil. Desenvolvimento sustentável: dimensões e desafios. Campinas, SP: Papirus, 2003.

CARVALHO, Isabel Cristina Moura. A invenção do sujeito ecológico: identidade e subjetividade na formação dos educadores ambientais. In: SATO, Michèle; CARVALHO, Isabel (Org.). Educaşão ambiental: pesquisa e desafios. Porto Alegre: Artmed, 2005.

CASCINO, Fabio. Educação ambiental: princípios, formação de professores. São Paulo: Editora SENAC, 2000.

DIAS, Genebaldo Freire. Educação ambiental: princípios e práticas. São Paulo: Gaia. 2004.

FOLADORI, Guillermo. A questão ambiental em Marx. Crítica Marxista. São Paulo: Xamã Editora, 1997. Volume 1, Tomo 4.

FOLADORI, Guillermo. Avanços e limites da sustentabilidade social. Revista paranaense de desenvolvimento. Curitiba, IPARDES, n. 102, 2002.

FOSTER, John Bellamy. A ecologia de Marx: materialismo e natureza. Trad. Maria Teresa Machado. Rio de Janeiro: Civilização Brasileira, 2005.

GADOTTI, Moacir. Pedagogia da terra. São Paulo: Peirópolis, 2000.

GOMES, Waldemarin Coelho; JIMENEZ, Susana. Pensamento complexo e concepção de ciência na pós-modernidade: aproximações críticas às "imposturas" de Edgar Morin. Revista Eletrônica Arma da Crítica, Ano 1, n. 1, Jan. 2009.

BRITTO, Luiz Percival Leme; OLIVEIRA, Magnólio. Ética e meio ambiente. Instituto Ecofuturo: uma proposta para o presente. 29 fev. 2008. Disponível em:

< http://www.ecofuturo.org.br/imprensa/titulo/amazonia/> Acesso em: agosto 2009. CHASIN, José. Democracia Política e Emancipação Humana. Revista Ensaio. n. 13. São Paulo: Editora Ensaio, 1984.

LAGO, Antônio; PÁDUA, José Augusto. O que é ecologia. São Paulo: Brasiliense, 2006.

LOUREIRO, Carlos F. B. Complexidade e dialética: contribuições à práxis política e emancipatória em educação ambiental. Revista Educação e Sociedade, v. 26, n. 93. Campinas, Sept./Dec. 2005. Disponível em:

$<$ http://www.scielo.br/scielo.php?script=sci_arttext\&pid=S0101-73302005000400020>.

LUKÁCS, Gyorgy. Per una ontologia dell'Essere Sociale. Roma: Riuniti, 1976-81.

MÉSZÁROS, István. Beyond capital. London: Merlin Press, 1995.

MÉSZÁROS, István. O século XXI: socialismo ou barbárie? Trad. Paulo Cezar Castanheira. São Paulo: Boitempo Editorial, 2003.

SAUVÉ, Lucie. Uma cartografia das correntes em educação ambiental. In: SATO, Michèle; CARVALHO, Isabel (Org.). Educação ambiental: pesquisa e desafios. Porto Alegre: Artmed, 2005.

PETRAS, James. Ensaios contra a Ordem. São Paulo: Página Aberta, 1995.

PETRAS, James. A crise do marxismo. Revista Crítica Marxista. v. 1, Tomo 7. São Paulo: Xamã, 1998.

TERTULIAN, Nicholas. Uma Apresentação à Ontologia do Ser Social de Lukács. Crítica 
Marxista n. 3. São Paulo: Brasiliense, 1996.

TONET, Ivo. Educação contra o capital. Maceió: Edufal, 2007.

TONET, Ivo; NASCIMENTO, Adriano. Descaminhos da esquerda

\section{Notas}

${ }^{1}$ Esta pesquisa vem sendo realizada com o apoio financeiro do CNPq e examina os paradigmas socioeducacionais que se conectam, de modo geral, ao Projeto de Educação para Todos. A Educação para Todos inaugura-se por ocasião da Conferência de Jomtien, em 1990, demarcando o estratégico papel que a educação deveria passar a desempenhar no enfrentamento dos graves problemas que estariam comprometendo o futuro milênio que, então, batia às nossas portas, garantindo, em última instância, a sustentabilidade global.

2 Para Nicholas Tertulian (1996, p. 94), um dos grandes estudiosos de Lukács, esse filósofo húngaro realiza, através de sua obra de maturidade, representada pela Estética e, posteriormente, pela Ontologia do Ser Social, a mais ambiciosa e a mais importante reconstrução filosófica do pensamento de Marx, superando duas severas distorções imputadas historicamente à herança marxiana: (1) o determinismo economicista que anula a eficácia dos demais complexos da vida social e (2) a interpretação teleológica dogmática - que considera toda ação histórica um passo no caminho da realização de um fim imanente ou transcendente.

${ }^{3}$ No decorrer dos encontros que precederam a Conferência de Estocolmo, foram identificadas, por um lado, posições reducionistas que apontavam para a exaustão dos recursos naturais e a impossibilidade tecnocientífica de superação desses limites (representadas pelos malthusianos); e, por outro, posições que sustentavam com veemência a possibilidade, por meios tecnológicos, de superação dos problemas relacionados ao esgotamento dos recursos naturais (os cornucopianos). A esse respeito, ver Camargo (2003, p. 65-66).

${ }^{4}$ Cf. Entenda os principais pontos do Protocolo de Kyoto. Disponível em: $<$ http://www1.folha.uol.com.br/folha/bbc/ult272u39714.shtml>. Acesso em: agosto 2009.

${ }^{5}$ Cumpre aqui ressaltar que o presidente dos Estados Unidos, Barack Hussein Obama, quando ainda em campanha eleitoral, prometera priorizar o meio ambiente na agenda presidencial, chegando a expressar seu apoio às medidas para combater o aquecimento global, como o crédito de carbono. Em recentes declarações, anunciou que disponibilizaria 2,4 bilhões de dólares para apoiar o desenvolvimento de automóveis elétricos, visando a reduzir a dependência do petróleo que vem do Oriente Médio, substituindo-o por energias renováveis e criando milhões dos chamados green jobs ou empregos ecológicos. Quanto à questão, tão polêmica, do aquecimento global, na página eletrônica do governo norte-americano, em que qualquer compatriota ou mesmo um cidadão mundial atento pode acompanhar as notícias da hora, lê-se da parte do Presidente Obama: “(...) as all of you know, [climate change] is something that my administration is deeply concerned about (...). We're looking forward to working with some of the major countries involved, to figure out how, even in the midst of economic 
crisis, we can move forward and prevent what could be longer-term ecological crises that could have a tremendously adverse effect on the international economy if we don't take action".

${ }^{6}$ Cf. Ética e Meio Ambiente. Disponível em:

< http://www.ecofuturo.org.br/imprensa/titulo/amazonia/>. Acesso em: agosto 2009

${ }^{7} \mathrm{O}$ autor também demonstra compartilhar dessa afeição quando se refere às experiências deslanchadas pela revolução soviética. Convém frisar que, na acepção de Mészáros (1995), entre outros teóricos marxistas, por um conjunto complexo de fatores tanto de ordem objetiva quanto subjetiva, entre os quais a impossibilidade de que tão heroico empenho revolucionário atingisse os países industrialmente mais desenvolvidos, ao lado da própria degenerescência stalinista, as sociedades constituídas naquele caldo históricosocial não consumaram, a rigor, o projeto socialista, vindo a configurar-se como sociedades híbridas, pós-capitalistas, conforme denominação do autor.

${ }^{8}$ Vale destacar que a teoria da complexidade, conforme referenciada por Gadotti, está associada à obra de Edgar Morin. O chamado pensamento complexo, formulado por Morin, busca, de acordo com Loureiro (2004, s/d), "superar os paradigmas simplificadores que operam a disjunção ser humano/natureza ou que reduzem o ser humano à natureza de modo indistinto". Associando a teoria da complexidade ao campo da Educação Ambiental, Loureiro realça a atualidade do referido paradigma, apresentando-o, ao lado da dialética marxista, como de fundamental relevância tanto "para a compreensão do modo como nos organizamos e historicamente nos constituímos enquanto seres biológicos e sociais" quanto para "o entendimento das bases teórico-metodológicas fundantes das pedagogias críticas, promotoras de processos emancipatórios e da ação política em busca de patamares societários que permitam requalificar concretamente a inserção humana na natureza”. Gomes e Jimenez (2009), por seu turno, divorciam os princípios norteadores da ontologia marxiana do arcabouço teórico da complexidade, o qual, para os autores, guardaria maiores afinidades com o universo do pós-modernismo.

9 Como bem elucida Lukács, no espírito da ontologia marxiana, a reprodução do ser social gesta-se sobre a base das demais esferas do ser - inorgânica e orgânica -, em um movimento ao mesmo tempo de continuidade e ruptura. Por conseguinte: "Per intendere, dunque, in termini ontologici corretti la riproduzione dell'essere sociale, occorre da un lato tener conto che il suo fondamento ineliminabile è l'uomo con la sua costituzione fisica, con la sua riproduzione biologica, e dall'altro non perdere mai di vista che la riproduzione si svolge in un ambiente la cui base è bensí la natura, ma che pure viene sempre più modificato dal lavoro, dall'attività degli uomini, cosicché la società nella quale si verifica realmente il processo riproduttivo dell'uomo sempre meno trova già 'pronte' nella natura le condizioni della propria riproduzione, che invece essa crea mediante la prassi sociale degli uomini” (LUKÁCS,1981, p. 146-147).

${ }^{10}$ Para comprovar suas interpretações, o autor lança mão da feliz passagem do filósofo alemão, quando, há aproximadamente um século e meio, clama, com as armas da crítica à propriedade privada, em favor da devida guarda do planeta para as futuras gerações: "Do ponto de vista de uma formação econômico-política superior, a propriedade 
privada do planeta nas mãos de indivíduos isolados parecerá tão absurda como a propriedade privada de um homem nas mãos de outro. Nem sequer toda sociedade, uma nação, mais ainda, todas as sociedades contemporâneas juntas são proprietárias da Terra. Somente são seus possuidores, seus usufrutuários, e devem melhorá-la, como boni patres familias, para as gerações futuras" (MARX apud FOLADORI, 1997, p. 145-146).

${ }^{11}$ Diversos autores contemporâneos têm se reportado à chamada crise do marxismo, ou, no dizer de Petras (1998, p. 147), "à capitulação de antigos esquerdistas diante da presença avassaladora e dos triunfos militares do capitalismo". $\mathrm{Na}$ avaliação do mesmo autor (1995, p. 63), "O recuo mundial dos intelectuais das posições marxistas para outras mais "realistas" e mais cômodas e úteis para sua carreira profissional, política ou pessoal, está intimamente relacionada com o declínio do poder do movimento da classe operária e com o poder ascendente do capital nas últimas década, tanto na esfera cultural quanto na econômica". José Chasin (1984), por seu turno, destaca a virada democrática que entornou o projeto revolucionário, operada no contexto da mesma capitulação. "Parece-me, de fato, que o trinado em fuga da democracia está substituindo a tônica da autoliberação dos homens", diz o autor (p. 48). Nessa mesma direção expressam-se Tonet e Nascimento (2009), que vêm, recentemente, de publicar uma obra voltada para a explicitação dos "descaminhos da esquerda".

Recebido: 30/03/09

Aprovado: 14/10/09

Contato:

Universidade Estadual do Ceará Instituto de Estudos e Pesquisas do Movimento Operário (IMO)

Av. Paranjana, 1700 Itaperi Fortaleza - CE CEP 60740-000 